\title{
Arduino-based night return mechanism for passive solar trackers
}

\author{
Willy Stephen Tounsi Fokui ${ }^{1}$, Destine Mashava ${ }^{2}$ \\ ${ }^{1}$ Department of Electrical Engineering, Pan African University Institute for Basic Sciences, Technology and Innovation, \\ Kenya \\ ${ }^{2}$ Department of Mechanical Engineering, Pan African University Institute for Basic Sciences, Technology and \\ Innovation, Kenya
}

\begin{tabular}{|c|c|}
\hline Article Info & ABSTRACT \\
\hline Article history: & Solar trackers are support platforms that keep photovoltaic panels facing the \\
\hline Received Jan 25, 2021 & sun by following the sun from dusk to dawn. There exist active solar trackers \\
\hline Revised Jul 5, 2021 & at make use of motors and gears to orientate the photovoltaic panels \\
\hline Accepted Jul 23, 2021 & towards the sun; and passive solar trackers that operate through the \\
\hline & solar trackers suffer from the lack of a night return mechanism and a slow \\
\hline Keywords: & $\begin{array}{l}\text { wake-up response in the mornings due to the limitations on the surface } \\
\text { inclination angle of the rack. This paper seeks to address these issues by }\end{array}$ \\
\hline Arduino & proposing an Arduino-based night return mechanism for passive solar \\
\hline Energy saving & trackers. An energy-saving heating element such as the ultra heating fabric \\
\hline Night return mechanism & $\begin{array}{l}\text { manufactured by WireKinetics Co. is installed on the west-side canister of } \\
\text { the tracker. Before dawn, the fabric is automatically heated and this will }\end{array}$ \\
\hline Passive solar trackers & force the refrigerant in the west-side canister to vaporize and cool in the east- \\
\hline Photovoltaic & side canister, forcing the tracker to return and face eastward before sunrise. \\
\hline Ultra heating & $\begin{array}{l}\text { The night return mechanism is designed and simulated using proteus } \\
\text { profesional. Simulation results show that this system can significantly } \\
\text { optimize the function of passive solar trackers. }\end{array}$ \\
\hline
\end{tabular}

This is an open access article under the CC BY-SA license.

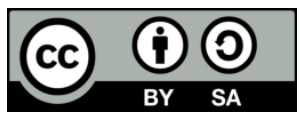

\section{Corresponding Author:}

Willy Stephen Tounsi Fokui

Department of Electrical Engineering

Pan African University Institute for Basic Sciences, Technology and Innovation

P.O. Box 62000-00200, JKUAT Main Campus, Nairobi, Kenya

Email: willysytis@gmail.com

\section{INTRODUCTION}

The sun is a huge source of energy. The amount of solar energy striking the top of the earth's atmosphere stands at 174 Petawatt, which is 10000 times the amount of energy humans use on this earth obtained from all possible sources such as coal, oil, natural gas, hydro, and nuclear combined [1]. If just $0.16 \%$ of the earth were covered by solar systems with an efficiency of $10 \%$, the solar systems will provide 20 Terawatt of energy, which is around twice what the world consumes from fossil sources [2]. Techniques such as the use of solar concentrators to convert solar energy into heat and then to electricity and photovoltaic panels which convert solar energy directly into electricity have been used to harvest energy from the sun [3].

Photovoltaic (PV) systems have significantly increased over the last decades, but their efficiency is still one of the top priorities for many academic and industrial research groups all over the world [4]. Due to the low efficiency of PV panels (still under 45\%), it is necessary to maximize the power output from the PV panels [5]. A good number of techniques have been developed to maximize the power output of PV panels among which the most common being solar trackers [6]. To maximize the output of PV panels, the panels 
have to be kept in an optimum position perpendicular to the solar radiation during the day, and this is achieved by using solar trackers.

Sun tracking systems are support platforms that orient photovoltaic module assemblies by keeping track of the sun's movement from dusk to dawn, thereby maximizing solar energy power generation efficiency [7]. The cosine of the angle between the sunlight and the PV panel is used to calculate the radiation value of sunlight acting on the solar panel's surface [8]. This, therefore, means that PV panels will produce maximum when sunlight is normal to their surface. This has led to the building of solar tracking systems or sun trackers. Solar tracking systems can boost the yield of solar panels by up to 50\% [9]. In fixed systems, the solar panels are placed to be in full direct sunshine at midday facing south in the northern hemisphere or facing north in the southern hemisphere [10]. In such settings, the panels will be hit by the sun at an acute angle, hence reducing the amount of energy generated daily [11]. Solar tracking systems were first introduced in 1962 by Finster and they were completely mechanical [12]. A year later, Saavadra presented a sun-tracking mechanism with automatic electronic control and it made use of orient an eppley pyrheliometer [13]. According to Awasthi et al. [14], solar trackers can be classified based on:

- driving system: active trackers and passive trackers

- the degree of freedom: single-axis tackers and dual-axis trackers

- control: closed-loop trackers and open-loop trackers

Passive solar trackers are of interest in this research. The working principle of passive trackers is well elaborated in [15]. Passive trackers are made up of a couple of actuators working against each other. In the case of equal illumination, they are balanced as shown in Figure 1(a) The rotation mechanism of the tracker is a result of the use of low boiling point compressed gas fluid that is moved by the solar heat that converts the liquid to gas, causing the tracker to tilt from one side to the other in the direction of the sun. When the actuators are exposed to different illuminations, unbalanced forces due to the gasification of the liquid orient the apparatus in the direction where the actuators will regain equal illumination and a balanced force restored. Tracking of the sun is begun by the racks facing westward as illustrated in Figure 1(b) since the sun rises in the east, an unshielded west side liquid-gas-filled canister is heated by the sun rays, forcing the liquid into the shaded east-side canister. The liquid moves through a copper tube to the east-side canister, thereby rotating the tracker to the east. Aluminum shaded plates are used to control the heating of the liquid. As one of the canisters gets exposed to the sun more than the other, an increase in its vapor pressure arises thereby forcing the liquid to the cooler, shaded side. The shifting weight of the liquid results in the rack rotating until the canisters are equally shaded.

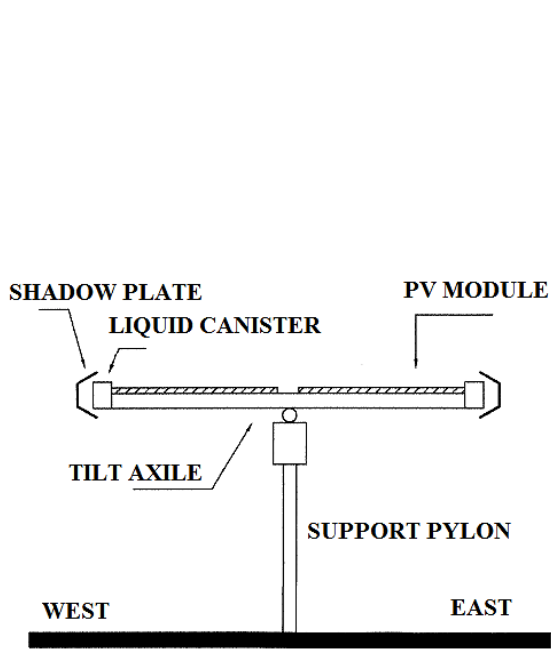

(a)
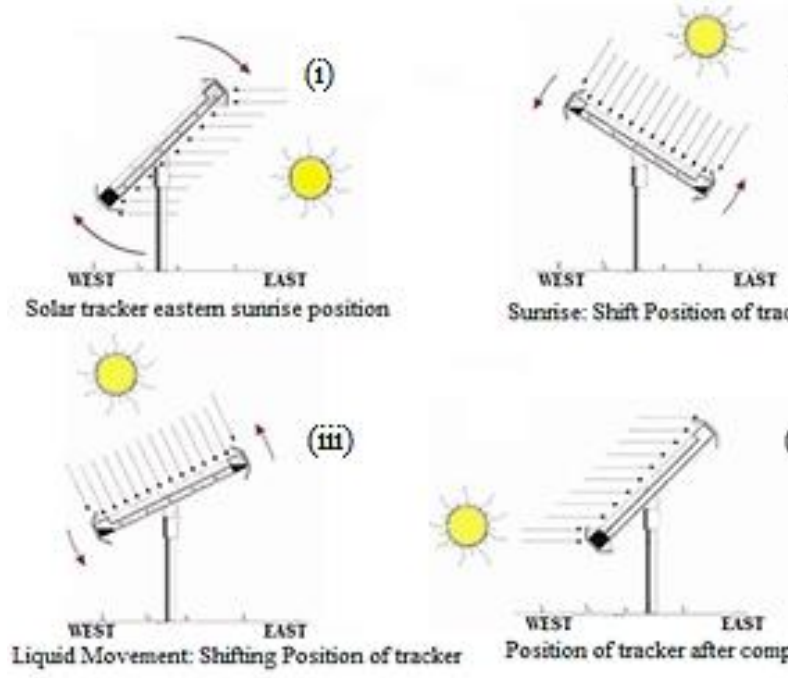

Sunise: Shift Position of tracker

(ii)

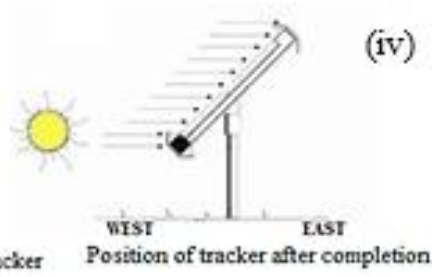

(b)

Figure 1. Passive solar tracker: (a) equal illumination of both canisters and (b) tracker daily operation

Passive solar tracking systems are less complex as compared to active solar trackers, but their efficiency is lower because their performance is affected by various climatic conditions such as temperature fluctuations, solar clouding, and at low temperatures, they stop working [4]. Nevertheless, they provide better 
output performance than fixed-angle solar systems [16]. Passive trackers have been advantageous over active trackers in that. Gravity is responsible for moving the tracker as a result of the differential heating of the liquid, low maintenance cost as a result of no motors and gears. On the other hand, the main problems passive solar trackers are facing are lack of an evening/night return mechanism and slow wake-up response in the mornings due to limitation on the surface inclination angle.

Quite some researches have been done to solve these two major problems. Clifford and Eastwood [17] presented a novel computer-based passive tracking system that incorporated two bimetallic strips made of aluminum and steel to absorb solar radiation. To prevent oscillation and excessive sluggishness of the system, a damper system was linked to the sun tracker. The computer-based passive solar design was implemented and an increased panel efficiency by up to $23 \%$ was observed. The solution could only solve the problem of slow wake-up response and at the end of the experiment, a night return mechanism was recommended. Baer [18], it is proposed the installation of mirrors on the eastside canister so that the mirrors will reflect the early morning sun onto the eastside canister. This solution though good can not be effective on all days due to early morning clouds on some days.

This paper seeks to design an Arduino-based night return mechanism solution for passive solar trackers. The proposed solution is the installation of an energy-saving heating element on the westside canister of the tracker which will be automatically heated at night and will force the rotation of the tracker to the east before sunrise. The rest of this paper is organized as follows; the next part is the methodology and this is followed by the simulation results and discussions. The last part is the conclusion and then references.

\section{RESEARCH METHOD}

It is required to choose an energy-saving heating element to heat the westside canister at night since all the refrigerant will be in that canister at that time. This will cause the refrigerant in that canister to vaporize and move to the east-canister thereby moving the tracker in the desired direction. To achieve this goal, the ultra heating (UH) fabric manufactured by WireKinetics Co., LTD is proposed. This fabric is a new generation electrical heating system that is specially designed for mobile heating, energy-saving, and safety orientated requirements and it uses direct current (DC) power [19]. The UH fabric adopts advanced smart textile technology. It is soft, light, thin, and strong since it is made up of metal-polymer composite conductive yarn which is perfectly integrated within the fabric by textile processes [19]. Figure 2(a) is shown structure of the ultra heating fabric, and Figure 2(b) is shown a roll of the ultra heating fabric [20].

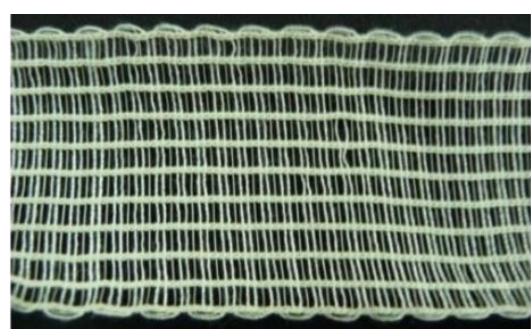

(a)

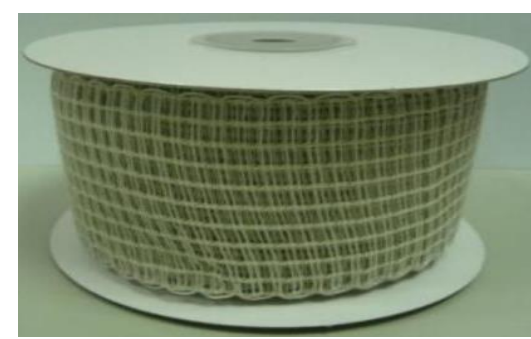

(b)

Figure 2. Ultra heating fabric by WireKinetics Co., LTD: (a) structure of the ultra heating fabric and (b) a roll of the ultra heating fabric

This UH fabric has the following properties [20]: width of $5 \mathrm{~cm}$, the diameter of the metal-polymer composite conductive yarn is about $0.27 \mathrm{~mm}$, the pitch of the conductive yarn in the fabric is about $5 \mathrm{~mm}$, wide range of operating voltages from $5 \mathrm{~V}$ to $12 \mathrm{Vdc}$

For a particular applied voltage, the output temperature of the fabric and the current drawn vary according to the length of the fabric. The longer the length, the lower the output temperature and the lower the current drawn, and vice versa. Tests were conducted by WireKinetics Co., LTD on the fabric using various voltage levels and fabrics of various lengths, and the results are presented in tabular forms shown in Tables 1 to 4 .

Table 1. Test results with $5 \mathrm{~V}$

\begin{tabular}{ccccccccccc}
\hline Length of the Fabric & $4 \mathrm{~cm}$ & $4.8 \mathrm{~cm}$ & $5.2 \mathrm{~cm}$ & $6.0 \mathrm{~cm}$ & $6.8 \mathrm{~cm}$ & $7.6 \mathrm{~cm}$ & $8.4 \mathrm{~cm}$ & $9.2 \mathrm{~cm}$ & $10.4 \mathrm{~cm}$ \\
\hline Current $(\mathrm{A})$ & 1.5 & 1.3 & 1.2 & 1.05 & 0.95 & 0.9 & 0.86 & 0.80 & 0.74 \\
Temperature $\left({ }^{\circ} \mathrm{C}\right)$ & 130 & 95 & 88 & 80 & 68 & 60 & 52 & 46 & 40 \\
\hline
\end{tabular}

Arduino-based night return mechanism for passive solar trackers (Willy Stephen Tounsi Fokui) 
Table 2. Test results with $7.4 \mathrm{~V}$

\begin{tabular}{ccccccccc}
\hline Length of the Fabric & $7.2 \mathrm{~cm}$ & $8 \mathrm{~cm}$ & $8.8 \mathrm{~cm}$ & $9.6 \mathrm{~cm}$ & $10.4 \mathrm{~cm}$ & $11.2 \mathrm{~cm}$ & $12 \mathrm{~cm}$ & $12.8 \mathrm{~cm}$ \\
\hline Current $(\mathrm{A})$ & 1.3 & 1.12 & 1.07 & 1.05 & 1.0 & 0.95 & 0.9 & 0.85 \\
Temperature $\left({ }^{\circ} \mathrm{C}\right)$ & 115 & 95 & 90 & 84 & 75 & 71 & 65 & 63 \\
\hline
\end{tabular}

Table 3. Test results with $9 \mathrm{~V}$

\begin{tabular}{cccccccc}
\hline Length of the Fabric & $8 \mathrm{~cm}$ & $8.8 \mathrm{~cm}$ & $9.6 \mathrm{~cm}$ & $10.4 \mathrm{~cm}$ & $11.2 \mathrm{~cm}$ & $12 \mathrm{~cm}$ & $12.8 \mathrm{~cm}$ \\
\hline Current $(\mathrm{A})$ & 1.3 & 1.25 & 1.18 & 1.1 & 1.06 & 1.02 & 1.0 \\
Temperature $\left({ }^{\circ} \mathrm{C}\right)$ & 110 & 108 & 100 & 91 & 86 & 82 & 73 \\
\hline
\end{tabular}

Table 4. Test results with $12 \mathrm{~V}$

\begin{tabular}{ccccccccc}
\hline Length of the Fabric & $9.6 \mathrm{~cm}$ & $10.4 \mathrm{~cm}$ & $11.2 \mathrm{~cm}$ & $12 \mathrm{~cm}$ & $12.8 \mathrm{~cm}$ & $20 \mathrm{~cm}$ & $32 \mathrm{~cm}$ & $40 \mathrm{~cm}$ \\
\hline Current $(\mathrm{A})$ & 1.4 & 1.33 & 1.27 & 1.25 & 1.22 & 0.9 & 0.66 & 0.52 \\
Temperature $\left({ }^{\circ} \mathrm{C}\right)$ & 123 & 110 & 106 & 104 & 102 & 80 & 55 & 42 \\
\hline
\end{tabular}

From the tables above, Table 4 is of interest in this study since most PV system batteries are 12 Vdc types. From Table 4 above, the fabrics of length $40 \mathrm{~cm}$ consume the least energy since it draws the least current. It is primordial that very little energy be consumed from the battery bank of the PV system. So, the fabric of length $40 \mathrm{~cm}$ was chosen. A $40 \mathrm{~cm}$ fabric will draw a current of 0.52 A to heat up to a temperature of $42^{\circ} \mathrm{C}$ in just a minute as shown in Figure 3. Passive solar trackers make use of low boiling point compressed gas fluids such as freon [21]. Therefore, this temperature is sufficiently high enough to displace the refrigerant of the tracking rack from the west-side canister to the east-side canister thereby rotating the tracker towards the east. An Arduino pro mini microcontroller is proposed to actuate the heating of the UH fabric at night and force it to return east before sunrise the following morning.

\subsection{Proposed system configuration}

On a track rack, a double $40 \mathrm{~cm}$ (80 cm total) UH fabric could be installed on the west-side canister and an end-of-tracking limit switch installed such that it is activated when the tracker completes its daily tracking journey at 6:00 pm as shown in Figure 4. The UH fabrics installed on the west-side canister of the tracker will force the system to operate as follows.

a. At the end of the day that is at dusk the passive tracker completes its tracking journey and ends up facing westward, and activates the end-of-tracking limit switch. The closing of the limit switch powers an Arduino pro mini microcontroller which instantly sees this as the end of the daily activity of the tracker and starts an internal timer and goes to sleep to save energy consumption. The microcontroller is only awakened 7 hours later by an internal timer overflow interrupt. This will be at around 1 am. The microcontroller heats the UH fabric on the west-side canister and this liquid-gas-filled canister will have a higher temperature than the east-side canister. This will lead to an increase in the vapor pressure of the refrigerant in the west-side canister thereby forcing the liquid to the cooler side (east-side canister). The liquid moves to the east-side canister through the copper tubes. The shifting weight of the liquid results in the rack rotating eastward (in the direction of sunrise). The returning of the tracker to the east will mean the end-of-tracking limit switch will be opened. Powering the Arduino from the limit switch is done through a timer relay which delays the powering off of the Arduino by 2 minutes when the limit switch is opened. This is sufficient time for the Arduino to have heated the fabric until the tracker is facing east. The Arduino pro mini microcontroller is then completely powered off. Therefore, the system does not consume the slightest power and is invisible to the passive tracker during normal day tracking operations.

b. The actuation of the night return at 1:00 am is to take care of situations of longer daylights which are mostly felt in countries in the north as well as those in the south of the Earth. Countries around the equator are not much affected. Also, it is preferable to wait until 1:00 am before actuating the night return journey of the tracker because should in case the PV panels on the tracker on that day did not produce sufficient power, let the little power produced be used for the purpose for which the panels were installed. Also, the Arduino pro mini going to sleep after being powered is done for energy saving purposes even though it is a low energy consuming device. It is important to minimize the power consumed by the night return mechanism to the fullest. 


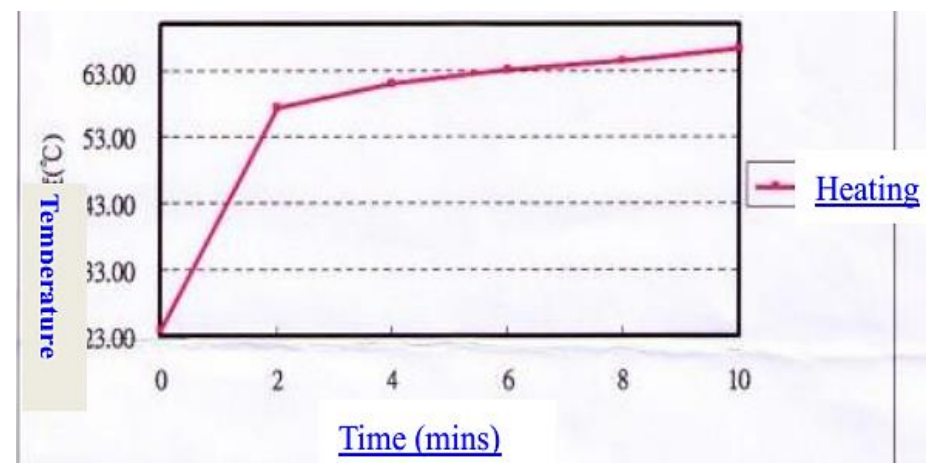

Figure 3. Temperature vs time graph of the UH fabric

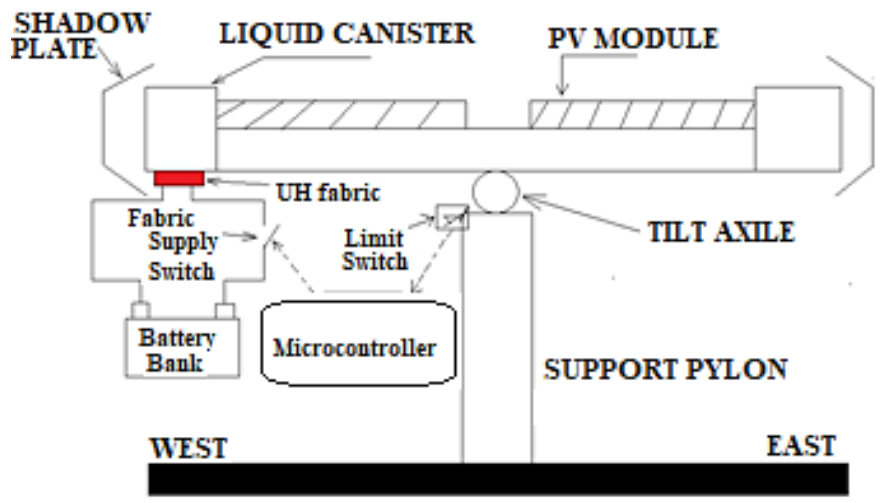

Figure 4. The proposed installation of the night return mechanism on the passive solar tracker

\subsection{Daily energy consumption of the UH fabrics during night return operation}

The UH fabric consumes very little energy since it is operated only for just 1 minute every day. The energy demand of the 2 fabrics, $E_{f}$ is given by (1).

$$
E_{f}=2 I V t
$$

Where $\mathrm{V}$ is the battery voltage, $\mathrm{I}$ is the fabric current and $\mathrm{t}$ is the operating time.

$$
E_{f}=2 I V t=(2)(0.52)(12)\left(\frac{1}{60}\right)=0.208 W h
$$

This energy is very small compared to what the PV system will produce hence we can say that this night return mechanism is energy saving.

\section{RESULTS AND DISCUSSION}

The simulation of the night return mechanism was done using proteus professional. A lightdependent resistor (LDR) with a torch is used to simulate sunlight. When the torch is drawn farther away from the LDR, the system sees it to be night and powers the Arduino pro mini microcontroller by the closing of the end-of-tracking limit switch which is simulated using the relay RL1 as shown in Figure 5. For simulation purposes, a $20 \times 4$ liquid crystal display (LCD) is used to show the state of the system. At the closing of the relay RL1 (end-of-tracking limit switch), a signal is sent to the Arduino and the Arduino immediately initiates an internal counter and this is displayed on the LCD as shown in Figure 6. For simulation purposes, the counting is done in seconds instead of hours. After 7 seconds, the UH fabric is powered and this is modeled by the actuation of a second relay, RL6, and the rotation of a DC motor as shown in Figure 7. During this moment, the LCD indicates that the tracker is returning to the east position. Upon successful return to facing east, the limit switch is opened and the LCD indicates that the tracker is now facing east and ready for the next day's sunrise. At this point, the counter is reset and the Arduino powered 
off. This is to avoid unnecessary energy consumption by the Arduino and also making it invisible to the tracker during normal operations.

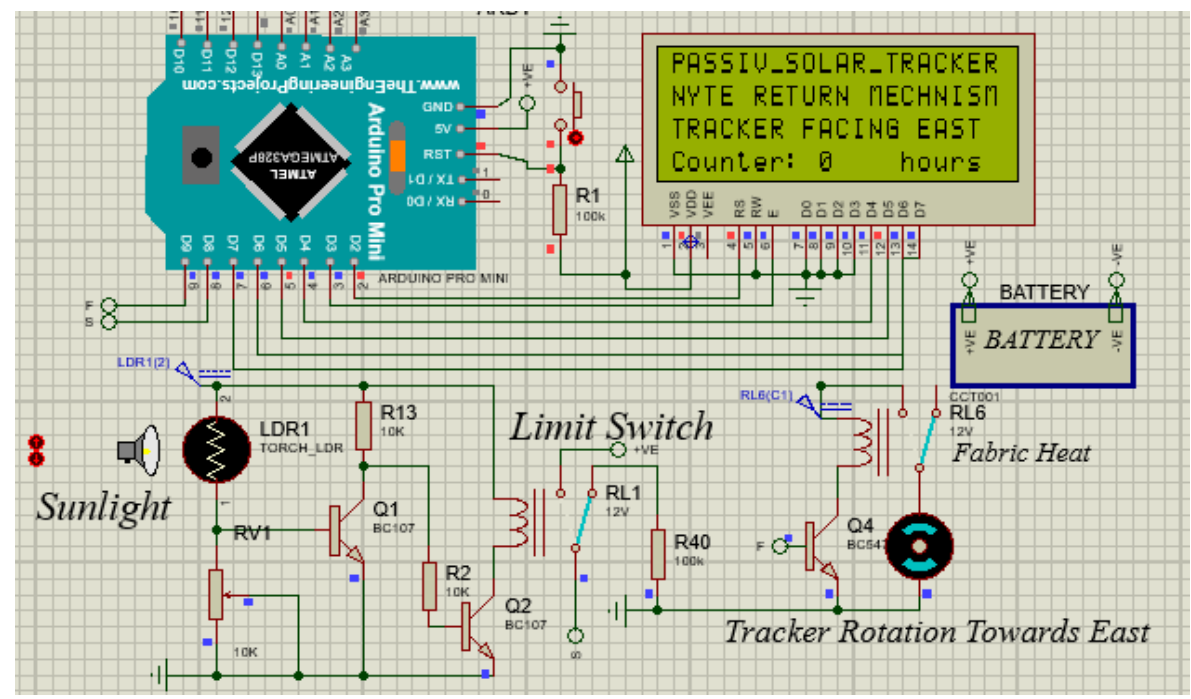

Figure 5. Simulation of the night return mechanism
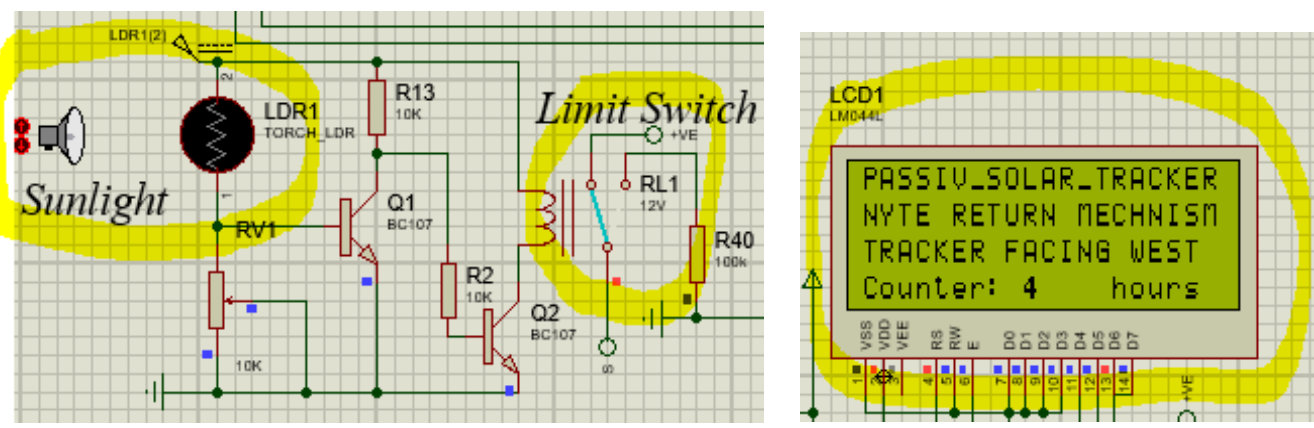

Figure 6. Nighttime, limit switch closed, counter initiated

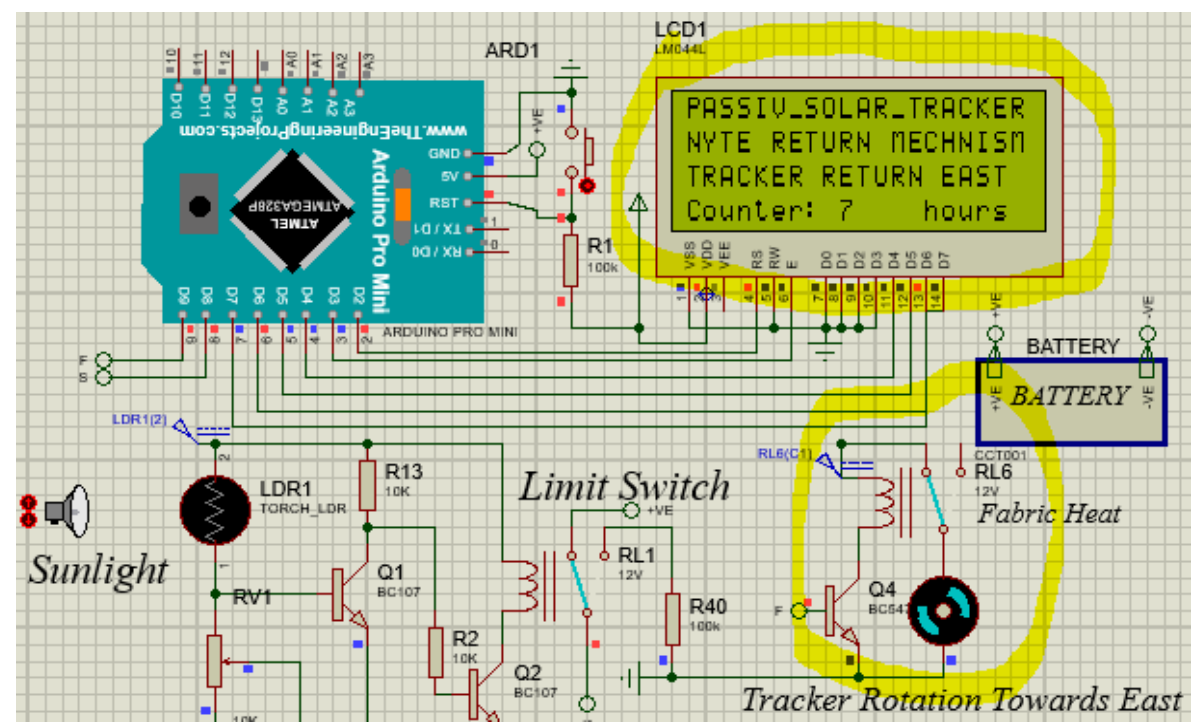

Figure 7. Tracker returns to facing east (sunrise position) 


\section{CONCLUSION}

Solar tracking systems are important mechanisms that enable an increase in the power yield of PV systems compared to fixed PV systems. They have proven their effectiveness in improving the output of PV systems by up to 50\%. Various categories of solar trackers exist among which are passive and active solar trackers. Passive solar trackers show to be advantageous to active solar trackers in the sense that they require low maintenance since they do not make use of motors and gears. Nevertheless, this tracking technique suffers from a slow wake-up response in the morning and has no night return mechanism. These problems have been addressed in this research by proposing a novel Arduino-based night return mechanism that heats up the liquid in the westside canister of the passive tracker at night forcing it to rotate eastward and face the sun before the sunrise. Simulation results showed the potentiality of the proposed system in returning a passive solar tracker to sunrise position for the next day's sunrise. Also, from calculations, it is seen that the night return mechanism consumes a very small amount of energy from the PV system batteries. Based on the obtained simulation results, it can be said that passive solar trackers if equipped with the proposed night return mechanism discussed in this paper will have the night return mechanism and low wake at dawn problems solved.

\section{REFERENCES}

[1] C. J. Rhodes, "Solar energy: Principles and possibilities," Science Progress, vol. 93, no. 1, pp. 37-112, 2010, doi: 10.3184/003685010X12626410325807.

[2] H. Mousazadeh, A. Keyhani, A. Javadi, H. Mobli, K. Abrinia, and A. Sharifi, "A review of principle and suntracking methods for maximizing solar systems output," Renewable and Sustainable Energy Reviews, vol. 13, no. 8, pp. 1800-1818, 2009, doi: 10.1016/j.rser.2009.01.022.

[3] M. Wasfi, "Solar Energy and Photovoltaic Systems," Journal of Selected Areas in Renewable and Sustainable Energy (JRSE), pp. 1-8, 2011, [Online]. Available: https://www.researchgate.net/publication/230651491.

[4] T. Tudorache and L. Kreindler, "Design of a solar tracker system for PV power plants," Acta Polytech. Hungarica, vol. 7, no. 1, pp. 23-39, 2010.

[5] P. Rani, O. Singh, and S. Pandey, "An Analysis on Arduino based Single Axis Solar Tracker," in 5th IEEE Uttar Pradesh Section International Conference on Electrical, Electronics and Computer Engineering, UPCON 2018, 2018, pp. 1-5, doi: 10.1109/UPCON.2018.8596874.

[6] V. Sumathi, R. Jayapragash, A. Bakshi, and P. Kumar Akella, "Solar tracking methods to maximize PV system output - A review of the methods adopted in recent decade," Renewable and Sustainable Energy Reviews, vol. 74, no. 2017, pp. 130-138, 2017, doi: 10.1016/j.rser.2017.02.013.

[7] H. Allamehzadeh, "An Update on Solar Energy and Sun Tracker Technology with a Dual Axis Sun Tracker Application," 2019 IEEE 46th Photovoltaic Specialists Conference (PVSC), 2019, pp. 2037-2044, doi: 10.1109/PVSC40753.2019.8981360.

[8] D. P. N. Nguyen and J. Lauwaert, "Calculating the energy yield of si-based solar cells for Belgium and Vietnam regions at arbitrary tilt and orientation under actual weather conditions," Energies, vol. 13, no. 12, p. 3180, 2020, doi: 10.3390/en13123180.

[9] H. Allamehzadeh, "Solar energy overview and maximizing power output of a solar array using sun trackers," 2016 IEEE Conference on Technologies for Sustainability (SusTech), 2016, pp. 14-19, doi: 10.1109/SusTech.2016.7897136.

[10] S. Amin, J. Hanania, K. Stenhouse, B. Yyelland, and J. Donev, "Solar Panel Orientation," Energy Education, 2018. accessed Jan. 21, 2021, [Online]. Available: https://energyeducation.ca/encyclopedia/Solar_panel_orientation.

[11] N. J. Parmar, A. N. Parmar, and V. S. Gautam, "Passive Solar Tracking System," International Journal of Emerging Technology and Advanced Engineering, vol. 5, no. 1, pp. 67-88, 2015.

[12] W. Nsengiyumva, S. G. Chen, L. Hu, and X. Chen, "Recent advancements and challenges in Solar Tracking Systems ( STS ): A review," Renewable and Sustainable Energy Reviews, vol. 81, pp. 250-279, 2018, doi: 10.1016/j.rser.2017.06.085.

[13] F. A. Khalil et al., "Solar tracking techniques and implementation in photovoltaic power plants: A review," Proceedings of the Pakistan Academy of Sciences: A. Physical and Computational Sciences, vol. 54, no. 3, pp. 231241, 2017. [Online]. Available: https://www.paspk.org/wp-content/uploads/2017/09/Solar-TrackingTechniques.pdf.

[14] A. Awasthi et al., "Review on sun tracking technology in solar PV system," Energy Reports, vol. 6, pp. 392-405, 2020, doi: 10.1016/j.egyr.2020.02.004.

[15] Zomeworks, "How Trackers Work," Zomeworks Corporation, accessed Jan. 21, 2021. [Online]. Available: http://www.zomeworks.com/photovoltaic-tracking-racks/how-trackers-work/.

[16] S. Seme, B. Štumberger, M. Hadžiselimović, and K. Sredenšek, "Solar photovoltaic tracking systems for electricity generation: A review," Energies, vol. 13, no. 6, p. 4224, 2020, doi: 10.3390/en13164224.

[17] M. J. Clifford and D. Eastwood, "Design of a novel passive solar tracker," Solar Energy, vol. 77, no. 3, pp. 269280, 2004, doi: 10.1016/j.solener.2004.06.009.

[18] S. C. Baer, "Gas spring solar tracker," U.S. Patent No. 4,476,854, 1984.

[19] WireKinetics Co., LTD "Fundamental of Heating," [Online] Available: https://wirekinetics.com/wpcontent/uploads/2021/06/Fundamental-of-Heating.pdf. (accessed Jan. 22, 2021). 
[20] WireKinetics Co., LTD, "Ultra Heating Fabric.” [Online] Available: https://wirekinetics.com/heating-fabric/.

[21] B. Asiabanpour et al., "Fixed versus sun tracking solar panels: an economic analysis," Clean Technologies and Environmental Policy, vol. 19, no. 4, pp. 1195-1203, 2017, doi: 10.1007/s10098-016-1292-y.

\section{BIOGRAPHIES OF AUTHORS}

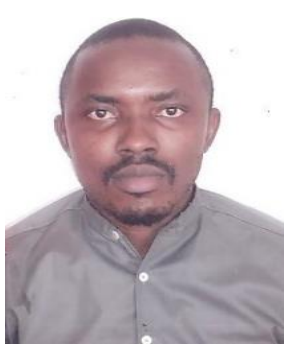

Willy Stephen Tounsi Fokui is a Ph.D. candidate in Electrical Engineering at the Pan African University Institute for Basic Sciences, Technology and Innovation, Kenya. He obtained his Bachelor of Engineering in Electrical and Electronic Engineering and Master of Engineering in Power Systems in the years 2014 and 2017 respectively. Both degrees were awarded by the University of Buea, Cameroon. His research interests include photovoltaic systems, energy management systems, distributed generation, and electric vehicle integration into the electrical distribution network.

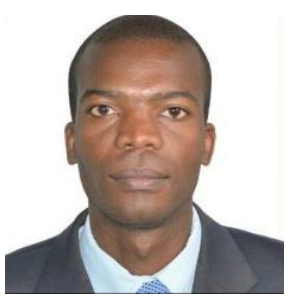

Destine Mashava is an M.Sc. candidate in Mechanical Engineering at the Pan African University Institute for Basic Sciences, Technology and Innovation, Kenya. He received his BEng (Hons) in Industrial and Manufacturing from the University of Science and Technology, Zimbabwe in 2016. His current research interests include machine learning, deep learning, Artificial Intelligence, condition monitoring, and automation. 